\title{
Temporal effects of cutting intensity on Diptera assemblages in eastern Borneo rainforest Indonesia
}

\author{
AHMAD BUDIAMAN ${ }^{1, \vartheta}$, NOOR FARIKHAH HANEDA ${ }^{2, \bullet v}$, INDAHWATI $^{3, \vee v \vee}$, DINI FEBRIAN ${ }^{1, \vee v \vee v, ~}$ \\ LAELA NUR RAHMAH \\ ${ }^{1}$ Department of Forest Management, Faculty of Forestry, Institut Pertanian Bogor. J1. Lingkar Akademik, Dramaga, Bogor 16680, West Java, Indonesia \\ Tel.:+62-251-8621244, Fax.: +62-251-8621256, ^email: budiaman@apps.ipb.ac.id, ^vvv dinifebrian10@gmail.com, vvvv laelanurahma@gmail.com \\ ${ }^{2}$ Department of Silviculture, Faculty of Forestry, Institut Pertanian Bogor. Jl. Lingkar Akademik, Dramaga, Bogor 16680, West Java, Indonesia. \\ Tel.: +62-251-8626806, Fax.: +62-251-8621256, ^^email: nhaneda@apps.ipb.ac.id \\ ${ }^{3}$ Department of Statistics, Faculty of Mathematics and Natural Sciences, Institut Pertanian Bogor. Jl. Meranti, Dramaga, Bogor 16680, West Java,

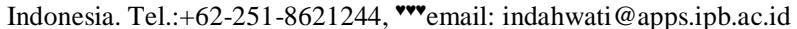

Manuscript received: 9 December 2019. Revision accepted: 17 February 2020

\begin{abstract}
Budiaman A, Haneda NF, Indahwati, Febrian D, Rahmah LN . 2020. Temporal effects of cutting intensity on Diptera assemblages in eastern Borneo rainforest Indonesia. Biodiversitas 21: 1074-1081. Studies on the effects of varying cutting intensity on the abundance and species richness of Diptera in tropical rainforest are limited, particularly in Southeast Asia region. The aim of the study was to assess the temporal effect of cutting intensity on Diptera community in tropical rainforest in the eastern Borneo rainforest, Indonesia, which was logged using the Indonesian Selective Cutting and Planting system. The field study was carried out in 2016. Responses of Diptera to the Indonesian Selective Cutting and Planting systems in the eastern Borneo rainforest, Indonesia were examined. We compared the abundance and morphospecies composition of Diptera before cutting and after cutting at three different treatments: low cutting intensity, medium cutting intensity and high cutting intensity. Diptera was collected using a malaise trap. Selective cutting of tropical rainforest altered biodiversity of Diptera. The abundance and morphospecies composition of Diptera were greater after cutting than before cutting at all cutting intensities. Our study showed that cutting intensity did not significantly affect the abundance and morphospecies composition of Diptera. Results of the study clearly indicated that the percentage of forest canopy cover could be a single predictor for abundance and morphospecies composition of Diptera in the natural rainforest of eastern Borneo, Indonesia.
\end{abstract}

Keywords: Flying insects, forest gaps, natural forest, tropical forest, selective logging

\section{INTRODUCTION}

Harvesting natural tropical rainforest with selective cutting systems for timber production is the greatest driver of forest disturbance (Willot et al. 2000; Franca et al. 2017), which affects rainforest biodiversity and has disrupted the ecosystem processes (Barlow et al. 2007; Ewers et al. 2015). Logging causes significant shifts in community composition, distribution, and abundance of species (Edwards et al. 2012; Franca et al. 2016). Post harvesting survey of a spectrum of tropical forests indicated a range of logging effects, from local extirpation to substantial increases in local densities of species (Bawa and Seidler 1998).

Degree of forest disturbance due to forest harvesting may be determined by cutting intensity (Burivalova et al. 2014). Previous studies reported that cutting intensity significantly changed forest canopy cover. Light cutting intensity might create tree fall gaps, whereas higher cutting intensity might create forest gaps (Bergstedt and Milberg 2001; Guitet et al. 2012). Forest openness affects the abundance and species richness of invertebrates (Koivula and Niemela 2003; Thorn et al. 2016). For example, sensitive dung beetle species may be lost following even low cutting intensity (Franca et al. 2017). Natural tropical rainforest in eastern Borneo, Indonesia, has been logged with selective cutting system since 1970. The cutting intensity that applied in the region was high, i.e. more than 10 trees per ha (Sist et al. 1998; Budiaman and Pradata 2013). Thus, there is a high potential threat to the invertebrate's community due to logging in the area. The role of timber concession in maintaining natural rainforest in Indonesia Borneo remains poorly characterized (Gaveau et al. 2013).

Insects play important roles in the functioning of ecosystem, such as a litter decomposition, seed predation and removal, and predation on other invertebrates (Ewers et al. 2015). In addition, the class Insecta is vast in numbers of species in comparison to other living organisms in the earth (Solis 1999). There may be more than 30 million species of insects in the earth (Godfray et al. 1999). Stork et al. (2015) produce independent estimates for all insects, mean: 5.5 million species (range 2.6-7.8 million), and for terrestrial arthropods, mean: 6.8 million species (range 5.97.8 million). Insects are still a frontier in scientific exploration (Solis 1999). However, our knowledge of the value of tropical forests for biodiversity conservation is limited to very few taxa (Grove and Stork 1999; Barlow et al. 2007). Furthermore, most studies of insects are dominated by investigation conducted in the temperate zones and boreal regions (Franca et al. 2016). Arthropod diversity in the rich terrestrial ecosystem, such as tropical 
rainforests, is still unknown (Basset et al. 2001) and poorly documented, although the tropical regions of the world generally have a rich store of biological diversity compared to other regions of the globe (Gadaghar et al. 1990).

Diptera is an order or insect that has the 4th largest number of species after Coleoptera, Lepidoptera, and Hymenoptera (Solis 1999), and often the most abundant species richness in forest microhabitats (Mlynarek et al. 2018), but Diptera receives less attention in the development of community diversity research (Didham 1997). Diptera commonly is known as flies. Diptera plays an important role in maintaining the dynamics of the forest ecosystem, such acting as decomposers, predators, parasites in insects, and pollinators (Byrd 2001), and can be used as bioindicators in environmental assessment (Larrier et al. 2015). Many of Diptera are known as insect pest groups for agriculture (Rostaman et al. 2007), responsible for the development of myiosis and pathogens to humans and animals (Caleffe et al. 2019), and carrier of diseases (Moirangthem et al. 2018). Studies on the impact of timber cutting on the abundance and species richness of Diptera at natural tropical rainforests are still limited and lags far behind compared to other insect groups. This study answers two research questions: (i) whether cutting of natural tropical rainforest with selective cutting systems affects the abundance and morphospecies composition of Diptera; (ii) whether there is a relationship between the intensity of cutting and environmental factors with the abundance and morphospecies composition of Diptera.

\section{MATERIALS AND METHODS}

\section{Study area}

The study was conducted in the secondary forest in one of the natural production forest concessions in Mahakam Hulu (Mahulu) District, East Kalimantan, Indonesia $\left(114^{\circ} 55^{\prime}-115^{\circ} 30^{\prime} \mathrm{E}\right.$ and $0^{\circ} 2^{\prime} \mathrm{S}-0^{\circ} 15^{\prime} \mathrm{N}$ ) (Figure 1). The forest has been logged using the Indonesian Selective Cutting and Planting. The forest concession harvested all commercial trees with a diameter at breast height of $>60$ $\mathrm{cm}$. The harvested trees were extracted by bulldozers and transported to log landing site or to the nearest forest road. The forest is dominated by dipterocarp species. The topography of study area was undulating. During fieldwork, average monthly precipitation was $312 \mathrm{~mm}$ and average daily temperature was $31.6^{\circ} \mathrm{C}$.

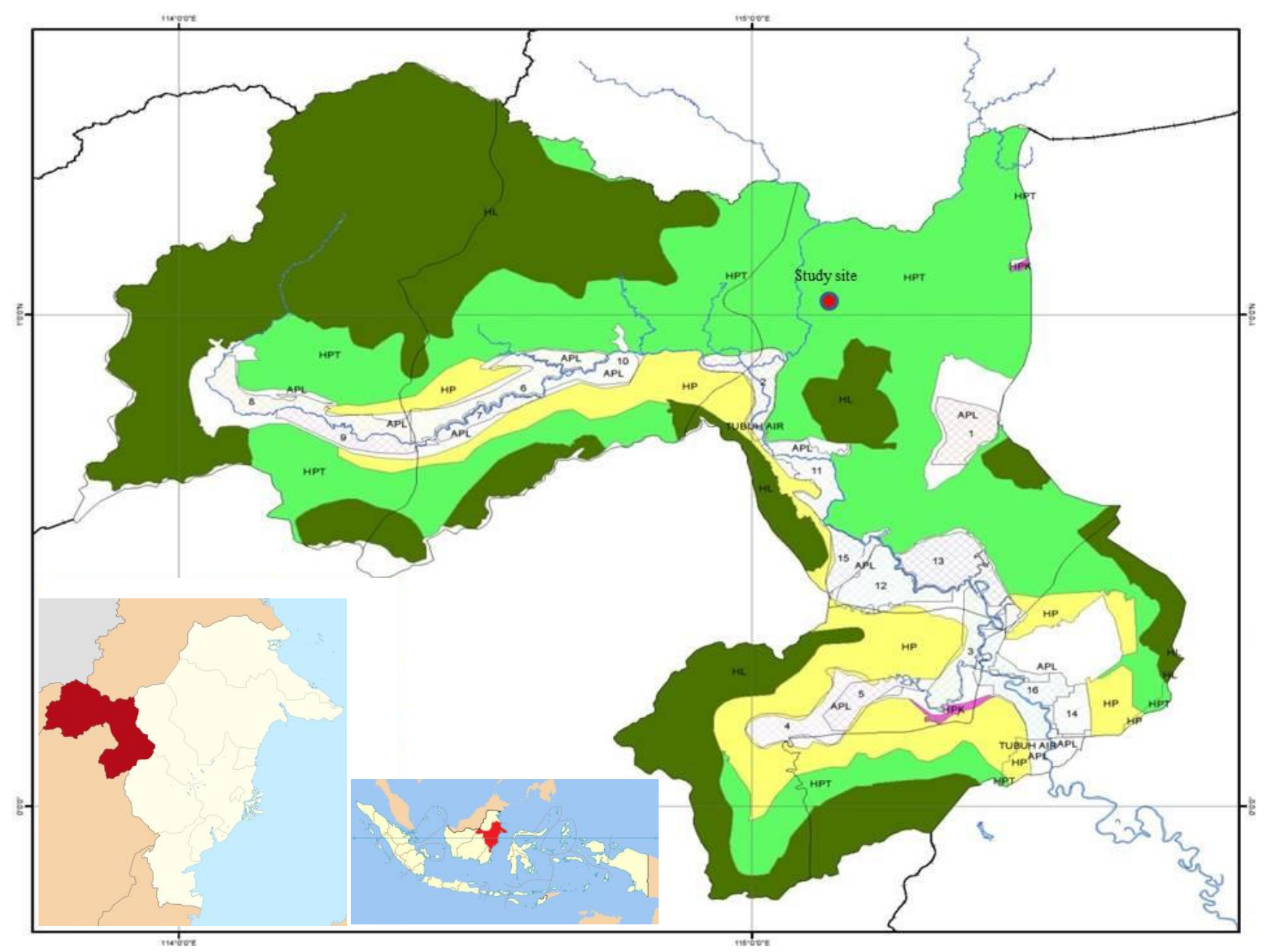

Figure 1. Study area in Mahulu District, East Kalimantan, Indonesia 


\section{Procedures}

Cutting intensity consisted of 3 levels: low cutting intensity $\left(4\right.$ trees ha $\left.{ }^{-1}\right)$, medium cutting intensity ( 8 trees ha $\left.{ }^{1}\right)$ and high cutting intensity (12 trees $\left.\mathrm{ha}^{-1}\right)$. In each treatment (cutting intensity) three circular plots of 0.5 ha were established in a study area of 98 ha. Insects were sampled using a malaise trap. Three malaise traps were arranged in a triangle design (north, southwest, and southeast direction) in the plot in distance of $20 \mathrm{~m}$ from the center of circular plot. Insects were collected 2 days before cutting and 2 days after cutting. The insects were sorted and Diptera subsequently identified to morphospecies level using the key of Borror et al. (1996). Air temperature, humidity, and forest canopy cover were measured 2 days before cutting and 2 days after cutting in each plot at the malaise trap placement point. A spiracle densitometer was used to record percentage of forest canopy cover. A digital thermohygrometer was used to measure air temperature and humidity. Insect samples were taken in dry season (April-June) in 2016.

\section{Data analysis and statistics}

The effects of cutting intensity and time of insect harvest on the abundance and morphospecies composition of Diptera were analyzed. The diversity index, species richness index, and evenness index were calculated for comparison between treatments before cutting and after cutting. We carried out two sets of analyses using the General Linear Model (GLM). The first examined the differences in abundance and morphospecies composition of Diptera between treatments before cutting and after cutting, and the second tested the relationship between the cutting intensity and environmental factors with the abundance and morphospecies composition of Diptera. The GLM was used because the data didn't follow the normal distribution. Data have been transformed to square root. The abundance and morphospecies composition of Diptera were response variables, whereas cutting intensity and time of insect harvest were determined as factors. Temperature, relative humidity, and forest canopy cover were included as a covariate in the model.

\section{RESULTS AND DISCUSSION}

\section{Abundance}

A total of 1705 individuals of Diptera were collected both before cutting (523 individuals) and after cutting (1182 individuals) in the study site (Table 1). The mean abundance of Diptera recorded after cutting was higher than before cutting at all cutting intensities (Figure 2). The mean abundance of Diptera before cutting and after cutting was significantly different at all cutting intensities $(\mathrm{p}<0.05)$. The mean abundance of Diptera at low, medium and high cutting intensity after cutting was 38.5 ind trap ${ }^{-1}$, 46.0 ind $\operatorname{trap}^{-1}$, and 46.7 ind $\operatorname{trap}^{-1}$ respectively, whereas before cutting was 12,9 ind $\operatorname{trap}^{-1}, 24.0$ ind trap ${ }^{-1}$, and 21.7 ind $\operatorname{trap}^{-1}$ respectively. The highest abundance for the first rank morphospecies was found after cutting (103 ind). ANOVA test results showed that there were no differences in the mean abundance of Diptera between cutting intensities. The mean abundance of Diptera at low, medium and high cutting intensity both before cutting and after cutting was similar.

\section{Morphospecies composition}

A total of 24 families of Diptera comprising 46 morphospecies were found in the study site. Eighteen (75\%) families were found both before cutting and after cutting. Three (12.5\%) families of Diptera (Dolichopodidae, Bombyliidae and Scatopsidae) were found only after cutting and three (12.5\%) families (Tachinidae, Hybotidae and Micropezidae) found only before cutting. The three most abundant families of Diptera before cutting were Cecidomyiidae (15.87\%), followed by Agromyzidae (12.24\%) and Mycetophilidae (11.09\%). The family rank of Diptera was changed after cutting. Mycetophilidae was the most abundant family after cutting (15.40\%), followed by Cecidomyiidae (15.14\%), Agromyzidae (12.24\%) and Tipulidae (12.44\%) (Table 1).

Table 1. Family, abundance and proportion of Diptera before cutting and after cutting in the study site, Mahulu District, East Kalimantan, Indonesia

\begin{tabular}{lcccc}
\hline \multirow{2}{*}{ Family } & \multicolumn{2}{c}{ Before cutting } & \multicolumn{2}{c}{ After cutting } \\
\cline { 2 - 5 } & $\begin{array}{c}\text { Abundance } \\
\text { (ind.) }\end{array}$ & $\begin{array}{c}\text { Proportion } \\
\text { (\%) }\end{array}$ & $\begin{array}{c}\text { Abundance } \\
\text { (ind.) }\end{array}$ & $\begin{array}{c}\text { Proportion } \\
(\%)\end{array}$ \\
\hline Cecidomyiidae & 83 & 15.87 & 179 & 15.14 \\
Agromyzidae & 64 & 12.24 & 147 & 12.44 \\
Mycetophilidae & 58 & 11.09 & 182 & 15.40 \\
Muscidae & 53 & 10.13 & 84 & 7.11 \\
Culicidae & 49 & 9.37 & 20 & 1.69 \\
Drosophilidae & 46 & 8.80 & 103 & 8.71 \\
Ephydridae & 45 & 8.60 & 84 & 7.11 \\
Sciaridae & 29 & 5.54 & 30 & 2.54 \\
Lauxaniidae & 27 & 5.16 & 49 & 4.15 \\
Tipulidae & 17 & 3.25 & 147 & 12.44 \\
Chironomidae & 10 & 1.91 & 28 & 2.37 \\
Calliphoridae & 7 & 1.34 & 2 & 0.17 \\
Phoridae & 7 & 1.34 & 14 & 1.18 \\
Rhagionidae & 7 & 1.34 & 2 & 0.17 \\
Anthomyzidae & 6 & 1.15 & 46 & 3.89 \\
Anisopodidae & 4 & 0.76 & 43 & 3.64 \\
Keroplatidae & 4 & 0.76 & 0 & 0.00 \\
Empididae & 3 & 0.57 & 14 & 1.18 \\
Tachinidae & 2 & 0.38 & 0 & 0.00 \\
Hybotidae & 1 & 0.19 & 0 & 0.00 \\
Micropezidae & 1 & 0.19 & 0 & 0.00 \\
Dolichopodidae & 0 & 0.00 & 6 & 0.51 \\
Bombyliidae & 0 & 0.00 & 1 & 0.08 \\
Scatopsidae & 0 & 0.00 & 1 & 0.08 \\
Total & 523 & 100.00 & 1182 & 100.00 \\
\hline & & & & \\
\hline
\end{tabular}


Table 2. Morphospecies of Diptera which found before cutting in the study site, Mahulu District, East Kalimantan, Indonesia

\begin{tabular}{|c|c|c|c|}
\hline Family & Morphospecies & $\begin{array}{l}\text { Abundance } \\
\text { (Ind.) }\end{array}$ & $\begin{array}{c}\text { Proportion } \\
(\%)\end{array}$ \\
\hline Culicidae & Culiseta sp. & 47 & 6.09 \\
\hline Drosophilidae & Drosophila sp. & 46 & 5.96 \\
\hline Ephydridae & Brachydeutera sp. & 45 & 5.83 \\
\hline Agromyzidae & Ophiomyia sp. & 40 & 5.18 \\
\hline Cecidomyiidae & Lestremiinae sp. & 40 & 5.18 \\
\hline Cecidomyiidae & Rhopalomyia sp. & 31 & 4.02 \\
\hline Muscidae & Hydrotaea sp. & 30 & 3.89 \\
\hline Sciaridae & Eugnoriste sp. & 29 & 3.76 \\
\hline Agromyzidae & Cerodontha sp. & 24 & 3.11 \\
\hline Mycetophilidae & Monoclona sp. & 19 & 2.46 \\
\hline Lauxaniidae & Homoneura sp. & 16 & 2.07 \\
\hline Mycetophilidae & Trichonta sp. & 12 & 1.55 \\
\hline Muscidae & Caricea sp. & 10 & 1.30 \\
\hline Chironomidae & Psectrotanypus sp. & 9 & 1.17 \\
\hline Tipulidae & Nephrotoma sp. & 9 & 1.17 \\
\hline Muscidae & Muscina sp. & 7 & 0.91 \\
\hline Rhagionidae & Rhagio sp. & 7 & 0.91 \\
\hline Mycetophilidae & Mycetophila sp. & 7 & 0.91 \\
\hline Phoridae & Conicera sp. & 7 & 0.91 \\
\hline Cecidomyiidae & Anaret sp. & 7 & 0.91 \\
\hline Mycetophilidae & Schiophilinae sp. & 7 & 0.91 \\
\hline Anthomyzidae & Eutrichonta sp. & 6 & 0.78 \\
\hline Mycetophilidae & Aglomyia sp. & 6 & 0.78 \\
\hline Lauxaniidae & Camptoprospella sp. & 6 & 0.78 \\
\hline Muscidae & Coenosia sp. & 5 & 0.65 \\
\hline Tipulidae & Dolichopeza sp. & 5 & 0.65 \\
\hline Lauxaniidae & Meiosimyza sp. & 5 & 0.65 \\
\hline Mycetophilidae & Sciophilinae sp. & 5 & 0.65 \\
\hline Keroplatidae & Macrocera sp. & 4 & 0.52 \\
\hline Anisopodidae & Sylvicola sp. & 4 & 0.52 \\
\hline Cecidomyiidae & Mycodiplosis sp. & 4 & 0.52 \\
\hline Calliphoridae & Cynomya sp. & 3 & 0.39 \\
\hline Empididae & Hemerodromia sp. & 3 & 0.39 \\
\hline Calliphoridae & Lucilia sp. & 2 & 0.26 \\
\hline Tachinidae & Tachinidae sp. & 2 & 0.26 \\
\hline Culicidae & Anopheles sp. & 2 & 0.26 \\
\hline Mycetophilidae & Leptomorphus sp. & 2 & 0.26 \\
\hline Tipulidae & Erioptera sp. & 2 & 0.26 \\
\hline Calliphoridae & Calliphora sp. & 1 & 0.13 \\
\hline Chironomidae & Chironomus sp. & 1 & 0.13 \\
\hline Hybotidae & Platypalpus sp. & 1 & 0.13 \\
\hline Micropezidae & Rainiera sp. & 1 & 0.13 \\
\hline Muscidae & Neodexiopsis sp. & 1 & 0.13 \\
\hline Calliphoridae & Protophormia sp. & 1 & 0.13 \\
\hline Cecidomyiidae & Aphidolates sp. & 1 & 0.13 \\
\hline Tipulidae & Cryptolabis sp. & 1 & 0.13 \\
\hline Total & & 523 & 100 \\
\hline
\end{tabular}

Total number of Diptera morphospecies found in the study site was 46 morphospecies. Thirty-five (76.1\%) morphospecies of Diptera were found both before cutting and after cutting. Eleven (23.9\%) morphospecies (Cynomya sp,. Lucilia sp., Calliphora sp., Anaret sp., Chironomus sp., Platypalpus sp., Macrocera sp., Rainiera sp., Neodexiopsis sp., Schiophilinae sp., and Tachinidae sp.) appeared only before cutting. The number of morphospecies of Diptera increased after cutting at all cutting intensities, ranging from 7-14 morphospecies. This increase may due to other morphospecies newly being present. There were ten new morphospecies of Diptera, which found only after tree
Table 3. Morphospecies of Diptera which found after cutting in the study site, Mahulu District, East Kalimantan, Indonesia

\begin{tabular}{|c|c|c|c|}
\hline Family & Morphospecies & $\begin{array}{l}\text { Abundance } \\
\text { (ind.) }\end{array}$ & $\begin{array}{c}\text { Proportion } \\
(\%)\end{array}$ \\
\hline Drosophilidae & Drosophila sp. & 103 & 10.70 \\
\hline Agromyzidae & Ophiomyia sp. & 92 & 9.55 \\
\hline Cecidomyiidae & Rhopalomyia sp. & 85 & 8.83 \\
\hline Ephydridae & Brachydeutera sp. & 82 & 8.52 \\
\hline Mycetophilidae & Trichonta sp. & 73 & 7.58 \\
\hline Cecidomyiidae & Mycodiplosis sp. & 65 & 6.75 \\
\hline Agromyzidae & Cerodontha sp. & 55 & 5.71 \\
\hline Tipulidae & Dolichopeza sp. & 49 & 5.09 \\
\hline Anthomyzidae & Eutrichonta sp. & 46 & 4.78 \\
\hline Anisopodidae & Sylvicola sp. & 43 & 4.47 \\
\hline Mycetophilidae & Leptomorphus sp. & 37 & 3.84 \\
\hline Mycetophilidae & Mycetophila sp. & 36 & 3.74 \\
\hline Lauxaniidae & Homoneura sp. & 34 & 3.53 \\
\hline Muscidae & Hydrotaea sp. & 34 & 3.53 \\
\hline Tipulidae & Cryptolabis sp. & 32 & 3.32 \\
\hline Tipulidae & Limonia sp. & 30 & 3.12 \\
\hline Sciaridae & Eugnoriste sp. & 30 & 3.12 \\
\hline Tipulidae & Erioptera sp. & 29 & 3.01 \\
\hline Chironomidae & Psectrotanypus sp. & 28 & 2.91 \\
\hline Muscidae & Coenosia sp. & 27 & 2.80 \\
\hline Cecidomyiidae & Lestremiinae sp. & 25 & 2.60 \\
\hline Mycetophilidae & Sciophilinae sp. & 18 & 1.87 \\
\hline Empididae & Hemerodromia sp. & 14 & 1.45 \\
\hline Phoridae & Conicera sp. & 14 & 1.45 \\
\hline Lauxaniidae & Camptoprospella sp. & 11 & 1.14 \\
\hline Muscidae & Muscina sp. & 12 & 1.25 \\
\hline Muscidae & Caricea sp. & 9 & 0.93 \\
\hline Culicidae & Culiseta sp. & 8 & 0.83 \\
\hline Mycetophilidae & Monoclona sp. & 7 & 0.73 \\
\hline Tipulidae & Nephrotoma sp. & 7 & 0.73 \\
\hline Culicidae & Culex sp. & 6 & 0.62 \\
\hline Dolichopodidae & Condylostylus sp. & 6 & 0.62 \\
\hline Culicidae & Anopheles sp. & 6 & 0.62 \\
\hline Mycetophilidae & Leia sp. & 5 & 0.52 \\
\hline Cecidomyiidae & Aphidolates sp. & 4 & 0.42 \\
\hline Lauxaniidae & Meiosimyza sp. & 4 & 0.42 \\
\hline Mycetophilidae & Ectrepeshoneura sp. & 3 & 0.31 \\
\hline Mycetophilidae & Aglomyia sp. & 3 & 0.31 \\
\hline Ephydridae & Discomyza sp. & 2 & 0.21 \\
\hline Muscidae & Neomyia sp. & 2 & 0.21 \\
\hline Rhagionidae & Rhagio sp. & 2 & 0.21 \\
\hline Bombyliidae & Anthrax sp. & 1 & 0.10 \\
\hline Calliphoridae & Chrysomya sp. & 1 & 0.10 \\
\hline Scatopsidae & Laboldia sp. & 1 & 0.10 \\
\hline Calliphoridae & Protophormia sp. & 1 & 0.10 \\
\hline Total & & 1182 & 100 \\
\hline
\end{tabular}

cutting. This morphospecies were Anthrax sp., Chrysomya sp., Culex sp., Condylostylus sp., Discomyza sp., Neomyia sp., Leia sp., Ectrepeshoneura sp., Laboldia sp., and Limonia sp.). The three most abundance of newly morphospecies of Diptera after cutting was Limonia sp. (3.12\% of the total individuals (Table 2 and 3). The mean morphospecies composition of Diptera at light, medium and high cutting intensity both before cutting and after cutting was similar (Figure 3). ANOVA test results showed that there were differences in the morphospecies composition of Diptera before cutting and after cutting $(\mathrm{p}<0.05)$. 


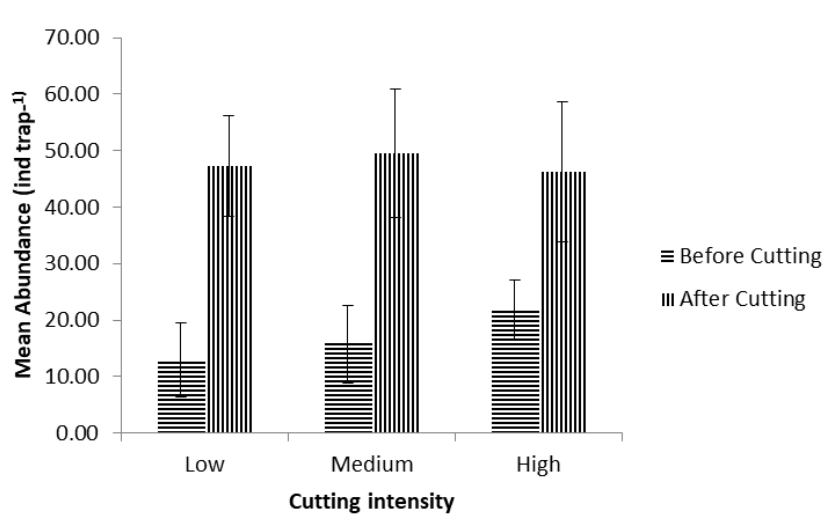

Figure 2. The mean abundance of Diptera before cutting and after cutting at three cutting intensity

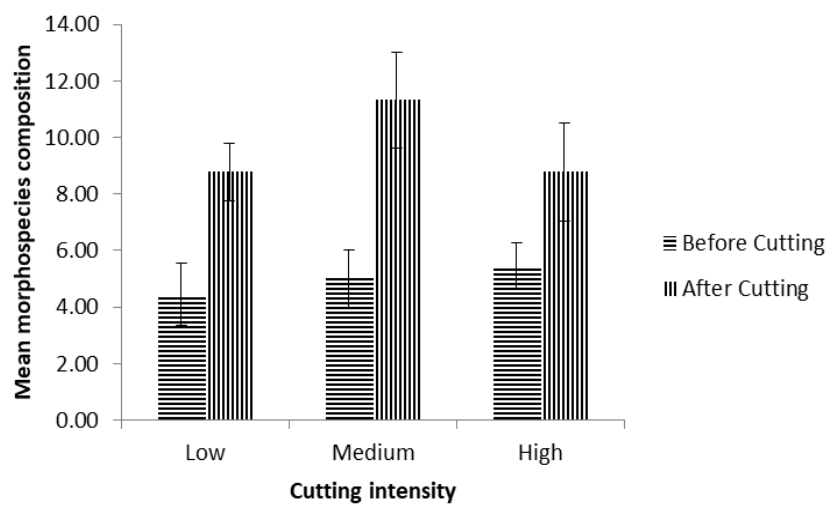

Figure 3. The mean morphospecies composition of Diptera before cutting and after cutting at three cutting intensity

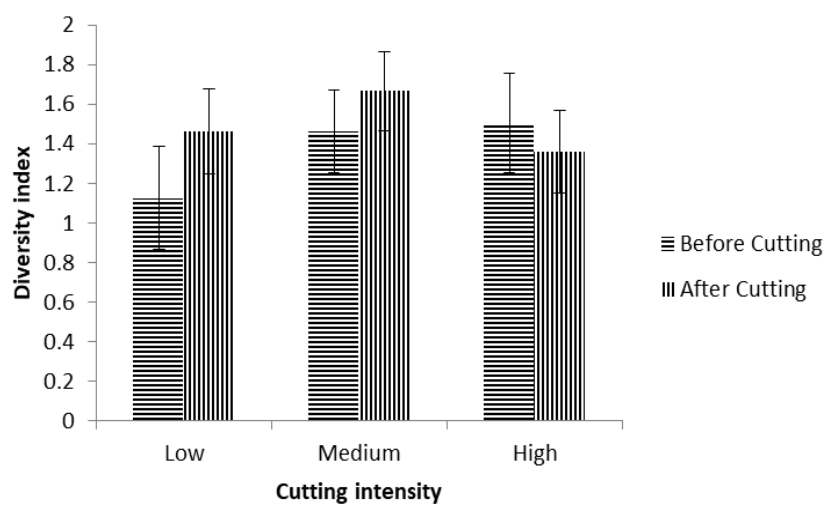

Figure 4. Diversity index of Diptera before cutting and after cutting at three cutting intensities

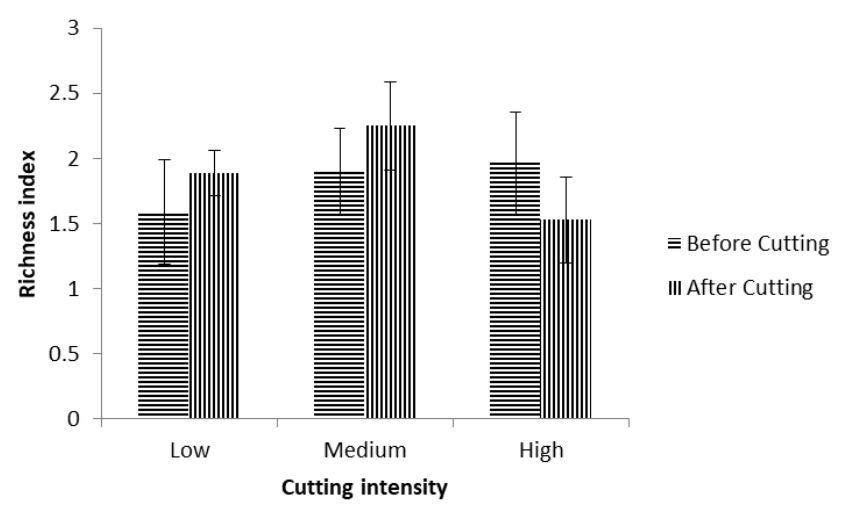

Figure 5. Species richness index of Diptera before cutting and after cutting at three cutting intensities

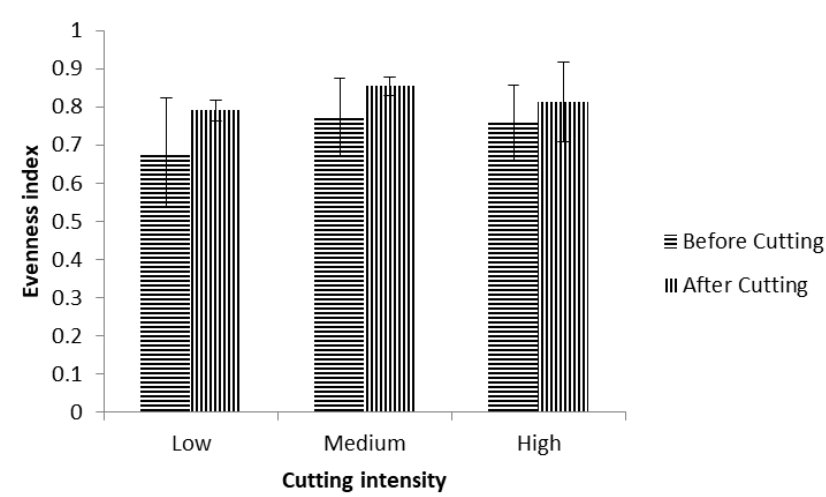

Figure 6. Evenness index of Diptera before cutting and after cutting at three cutting intensities

The highest abundant of Diptera morphospecies before cutting was Culiseta sp. (6.09\% of the total individuals), and the least abundant was Calliphora sp., Chironomus sp., Platypalpus sp., Rainiera sp., Neodexiopsis sp., Protophormia sp., Aphidolates sp., and Cryptolabis sp. $(0.13 \%$ of total individuals). Meanwhile, the highest abundance of Diptera morphospecies after cutting was Drosophila sp. (10.7\% of the total individuals), and the least abundant was Anthrax sp. Chrysomya sp. Laboldia sp. Protophormia sp. (0.01\% of the total individuals) (Table 2).

Table 4. Average daily temperature, humidity and forest canopy cover before cutting and after cutting at three cutting intensities

\begin{tabular}{lcccccc}
\hline \multirow{2}{*}{ Cutting intensity } & \multicolumn{2}{c}{ Temperature $\left({ }^{\circ} \mathbf{C}\right)$} & \multicolumn{2}{c}{ Humidity $(\%)$} & \multicolumn{2}{c}{ Forest canopy cover $(\%)$} \\
\cline { 2 - 7 } & Before cutting & After cutting & Before cutting & After cutting & Before cutting & After cutting \\
\hline Light & 32 & 32 & 75 & 75 & 82 & 62 \\
Medium & 30 & 33 & 76 & 75 & 83 & 59 \\
High & 31 & 33 & 79 & 77 & 80 & 54 \\
\hline
\end{tabular}


Table 5. Analysis of variance between abundance of Diptera and environmental factors, time of insect harvest (before cutting and after cutting), and cutting intensity

\begin{tabular}{lccccc}
\hline \multicolumn{1}{c}{ Source } & DF & Adj SS & Adj MS & $\begin{array}{c}\text { F- } \\
\text { Value }\end{array}$ & $\begin{array}{c}\text { P- } \\
\text { Value }\end{array}$ \\
\hline Temperature & 1 & 6.870 & 6.870 & 1.05 & $0.312^{\text {ns }}$ \\
Humidity & 1 & 12.846 & 12.846 & 1.96 & $0.169^{\text {ns }}$ \\
Forest canopy cover & 1 & 36.784 & 36.784 & 5.60 & $0.022^{*}$ \\
Time of insect harvest & 1 & 72.065 & 72.065 & 10.97 & $0.002^{*}$ \\
Cutting intensity & 2 & 8.473 & 4.236 & 0.64 & $0.529^{\text {ns }}$ \\
Error & 47 & 308.768 & 6.569 & & \\
Total & 53 & 400.911 & & & \\
\hline Not & & & & & \\
\hline
\end{tabular}

Note: ns: not significant; *: significant $(\alpha=5 \%)$

Table 6. Analysis of variance between morphospecies composition of Diptera and environmental factors, time of insect harvest (before cutting and after cutting), and cutting intensity

\begin{tabular}{lccccc}
\hline \multicolumn{1}{c}{ Source } & DF & Adj SS & $\begin{array}{c}\text { Adj } \\
\text { MS }\end{array}$ & $\begin{array}{c}\text { F- } \\
\text { Value }\end{array}$ & $\begin{array}{c}\text { P- } \\
\text { Value }\end{array}$ \\
\hline Temperature & 1 & 0.163 & 0.163 & 0.26 & $0.611^{\text {ns }}$ \\
Humidity & 1 & 0.577 & 0.577 & 0.93 & $0.340^{\text {ns }}$ \\
Forest canopy cover & 1 & 2.110 & 2.110 & 3.39 & $0.072^{\text {ns }}$ \\
Time of insect harvest & 1 & 6.106 & 6.106 & 9.81 & $0.003^{*}$ \\
Cutting intensity & 2 & 0.874 & 0.437 & 0.70 & $0.501^{\text {ns }}$ \\
Error & 47 & 29.239 & 0.622 & & \\
Total & 53 & 38.648 & & & \\
\hline
\end{tabular}

Note: ns: not significant; *: significant $(\alpha=5 \%)$

\section{Community indices}

The mean value of diversity, species richness, and evenness index of Diptera before cutting and after cutting at all cutting intensity was similar. The lowest mean value in the diversity index was found at low cutting intensity before cutting (1.13) and the highest value at medium cutting intensity after cutting (1.67) (Figure 4). For the richness index, the lowest mean value was recorded at high cutting intensity after cutting (1.53) and the highest value at medium cutting intensity after cutting (2.25) (Figure 5). Meanwhile, the lowest mean value in the evenness index was recorded at low cutting intensity before cutting (0.68) and the highest value at medium cutting intensity after cutting (0.85) (Figure 6).

\section{Environmental factors}

Logging of natural tropical rainforest with selective cutting system causes a decrease in canopy cover and humidity, as well as an increase in air temperature. The average daily temperature tended to increase after cutting in the study site. The average daily temperature before cutting was $30.7^{\circ} \mathrm{c}$, meanwhile after cutting was $32.6^{\circ} \mathrm{C}$. The average air humidity before cutting was $77.6^{\circ} \mathrm{c}$, meanwhile after cutting was $75.0^{\circ} \mathrm{C}$. The increase in cutting intensity tended to decrease air humidity. The environmental factor that changed drastically due to tree cutting was the percentage of canopy cover. The percentage of canopy cover reduced after cutting at all cutting intensities, ranged from 10-26\% (Table 4). The abundance of Diptera after cutting was higher than before cutting. The abundance and composition morphospecies of Diptera after cutting was related to the percentage of canopy cover. ANOVA results showed that air temperature and humidity did not significantly affect the abundance and morphospecies composition of Diptera, but the percentage of canopy cover significantly affected the abundance and morphospecies composition of Diptera at significance level of $5 \%$ (Table 5 and 6).

\section{Discussion}

Previous studies have shown a wide variation of the effect of forest cutting on insects (Soler et al. 2016; Stork et al. 2017). Sensitives dung beetle species may be lost following even low cutting intensity (Franca et al. 2017), however, Lewis (2001) found that selective logging had little effect on the abundance and species richness of fruitfeeding butterflies. Our study showed that selective cutting of the tropical rainforest significantly affects the abundance and morphospecies composition of Diptera. The abundance and morphospecies composition of Diptera after cutting were higher than before cutting. The abundance and morphospecies composition of Diptera after cutting increased at all three cutting intensities. However, the cutting intensity didn't significantly affect the abundance and morphospecies composition of Diptera. Diptera has functional roles such as detritivore, predator, herbivore, pollinator, and fungivore. More than $50 \%$ of Diptera found at the study site were a detritivore, while the rest as herbivore, fungivore, predator, and pollinator. Diptera pollinator was the least Diptera that found at the study site. Diptera detritivore belonged to the family Calliphoridae, Cecidomyiidae, Drosophilidae, Muscidae, and Tipulidae, while Diptera herbivore belonged to Chironomidae and Ephydridae. Pollinator Diptera belonged to Empididae and fungivore belonged to Mycetophilidae. Diptera included in predator came from a family of Dolichopodidae. The study showed that the abundance of detritivore Diptera after cutting increases 2.5 times of those before cutting. The abundance of detritivore Diptera was associated with the time of insect harvest (after cutting). Selective logging in the Indonesian tropical rainforest, even with low cutting intensity (one tree $\mathrm{ha}^{-1}$ ), produced relatively high logging waste (ranging from 4.98-5.55 $\mathrm{m}^{3} \mathrm{ha}^{-1}$ ). The common type of logging residue was stump, broken stem, fallen trees, branches, twigs and leaves (Budiaman et al. 2020). The presence of these dead woods may promote high-quality detritus which would support great abundance and diversity of detritivore (Cortez et al. 2007). Besides, forest habitat with open area, humid condition, and presence of understorey plants, which established after cutting, may support a great abundance of detritivore Diptera. O'Brien et al. (2017) found that abundance and richness of detritivore were significantly higher in the understorey than in the canopy.

The presence of insects in forest ecosystems was influenced by environmental factors, such as temperature, humidity and canopy cover (Niemela 1997; Didham 1997). Only the percentage of canopy cover showed a significant 
effect on the abundance of Diptera in the study site. The more abundant Diptera found after cutting. Selective cutting led to open canopy cover. The forest habitat after cutting had a lower percentage of canopy cover than before cutting. ANOVA result showed that the percentage of canopy cover significantly affect the abundance and morphospecies composition of Diptera at 5\% significant level. Our results showed a similar trend compared to previous studies. Didham (1997) reported that canopy cover was the single best predictor of variation in abundance of Diptera. Close proximity to the forest edge and low percentage canopy cover were important determinants of high abundance and diversity of Diptera. The abundance of canopy-dwelling Diptera was higher in the more open canopy than closed canopy in the New Zealand rainforest. These species may be using the canopy for such purposes as mating, avoiding predators or suitable microclimate conditions for resting sites, or as a path to other habitats. The abundance of Diptera increased with the number of forest gaps (Okland 1996; van Hoesel et al. 2012). Gittings et al. (2006) found that the majority (80\%) of hoverflies (Diptera, Syrphidae) species were associated with open space habitats rather than a closed-canopy forest. Also, Gossner (2009) reported that the diversity of flying insects was affected by canopy cover, but the response depended on the vertical position. Insect diversity increased significantly close to the forest floor with decreasing canopy cover.

The results showed that the cutting intensity didn't affect the abundance and morphospecies composition of Diptera. The increase in abundance and morphospecies composition at low, medium and high cutting intensity was similar. Although higher cutting intensity, more trees are cut, it does not change drastically the forest habitat around the felled tree. The highest mean number of felled trees in the plot was 12 trees ha $^{-1}$, while the mean unfelled trees were 20 trees $\mathrm{ha}^{-1}$. Therefore, the number of trees where Diptera search for food and nest was still sufficient. The results of this study are consistent with the previous study. Okland (1996) found that tree cover appeared to be one of an important factor for preserving the diversity of Mycetophilids (Diptera, Sciaroidae) in the boreal forests. High levels of forest damage did not negatively affect all insects' taxa (Davis et al. 2001; Koivula and Niemela 2003).

Our result showed that Diptera morphospecies has a different response due to selective cutting. Based on its response to selective cutting, Diptera in the study site may be classified into three groups. The first group wasDiptera which is not disturbed due to selective cutting. This group was found both before cutting and after cutting. This morphospecies may be classified as more stress-tolerance morphospecies (Durska 2015). Most of the collected Diptera found in the study site was more stress-tolerance morphospecies. There were $76 \%$ of Diptera morphospecies, which found both before cutting and after cutting. The second group was Diptera which prefers closed habitats. These Diptera groups only found before cutting and recorded around $10 \%$ of total individuals. The last group wasDiptera which is found only after cutting. This group may be classified as open habitats species (Koivula and Niemela 2003). 26\% of total individuals Diptera found in the study site were open habitats morphospecies.

Selective cutting in the tropical rainforest changed the abundance and morphospecies composition of Diptera. The cutting intensity did not affect the abundance and morphospecies composition of Diptera. The abundance and morphospecies composition of Diptera increased after cutting. Canopy cover was a single environmental factor that affects the abundance and morphospecies composition of Diptera in the natural tropical rainforest of Borneo, Indonesia.

\section{ACKNOWLEDGEMENTS}

The authors would like to thank Ratah Timber Forest Company for providing technical support, facilities, accommodation, and sharing data.

\section{REFERENCES}

Barlow J, Gardner TA, Araujo IS, Avila-Pires TC, et al. 2007. Quantifying the biodiversity value of tropical primary, secondary and plantation forests. Proc Natl Acad Sci USA 104: 18550-18560.

Basset Y, Charles E, Hammond DS, Brown VK. 2001. Short-term effects of canopy openness on insect herbivores in rain forests in Guyana. J Appl Ecol 38: 1045-1058.

Bawa KS, Seidler R. 1998. Natural forest management and conservation of biodiversity in tropical forests. Conserv Biol 12: 46-55.

Bergstedt J, Milberg P. 2001. The impact of logging intensity on fliedlayer vegetation in Swedish boreal forests. For Ecol Manag 154: 105115 .

Borror DJ, Triplehorn CA, Johnson NF. 1996. An Introduction to The Study of Insects. Harcourt Brace College Publisher. New York.

Budiaman A, Pradata A. 2013. Low impact cutting distance and allowable number of felled trees in Indonesian Selective Cutting and Planting system. J Trop For Manag 19: 194-200.

Budiaman A, Mubarak FM, Lismaya W. 2020. Logging residues of low harvest intensity in Indonesian forest concession. J Ind Agric Sci 25: 145-151.

Burivalova Z, Seherciaglu CH, Koh LP. 2014. Threshold of logging intensity to maintain tropical forest biodiversity. Conserv Biol 24: 1893-1898.

Byrd JH, James LC. 2001. Insects of forensic importance. In: Forensic Entomology: The Utility of Arthropods in Legal Investigation. CRC Press. New York.

Caleffe RRT, de Oliveira SR, Schaffen RP, Junior VAO, Conte H. 2019. Biological control of Diptera (Calliphoridae): A review. J Entomol Res Soc 21: 145-155.

Cortez J, Garnier E, Pferez-Harguindeguy N, Debussche M, Gillon D. 2007. Plant traits, litter quality and decomposition in a Mediterranean old-field succession. Plant Soil 296: 19-34.

Davis AJ, Holloway JD, Huijbregts H, Krikken J, Kirk-Spriggs AH, Sutton SL. 2001. Dung beetles as indicators of change in the forests of northern Borneo. J Appl Ecol 38: 593-616.

Didham RK. 1997. Dipteran tree-crown assemblages in a diverse southern temperate rainforest. In: Stork NE, Adis J, Didham RK (eds). Canopy Arthropods. Chapman \& Hall, London.

Durska E. 2015. Effects of fire on scuttle flies (Diptera: Phoridae) in a pine forest in Polland. Entomol Fenn 26: 181-193.

Edwards FA, Chung A, Larsen TH, Hsu WW, Hamer KC. 2012. Does logging and forest conversion to oil palm agriculture alter functional diversity in a biodiversity hotspot?. Anim Conserv 17: 163-173.

Ewers RM, Boyle MJW, Gleave RA, Plowman NS, et. al. 2015. Logging cuts the functional importance of invertebrates in tropical forests. Nat Commun 7836. 
Franca F, Barlow J, Araujo B, Louzada J. 2016. Does selective logging stress tropical invertebrates? Using fat stores to examine sub-lethal responses in dung beetles. Ecol Eval Anim Conserv 17: 163-173.

Franca F, Frazo FS, Korasaki V, Louzda J, Barlow J. 2017. Identifying thresholds of logging intensity on dung beetle communities to improve the sustainable management of Amazonian tropical forests. Biol Conserv 216: 115-122.

Gadaghar R, Chandrashekara K, Nair P. 1990. Insect species diversity in the tropics: Sampling methods and a case study. J Bombay Nat Hist Soc 87: 337-353.

Gaveau DLA, Kshatriya M, Shell D, Siloan S, Molidena E, Wijaya A, Wich S, Acrenaz M, Hansen M, Broich M, Guariguata MR, Pacheco P, Polapov P, Turubanova S, Meijaard E. 2013. Reconciling forest conservation and logging in Indonesia Borneo. PLoS ONE 8 (8) e69887. DOI: 10.1371/journal.pone.0069887.

Gittings T, O’Halloran J, Kelly T, Giller PS. 2006. The contribution of open spaces to the maintenance of hoverfly (Diptera, Syrphidae) biodiversity in Irish plantation. For Ecol Manag 237: 290-300.

Gossner MM. 2009. Light intensity affects spatial distribution of Heteroptera in deciduous forests. Euro J Entomol 106: 241-252.

Godfray HCJ, Lewis DT, Memmott J. 1999. Studying insects in the tropics. Phil Trans Res Soc Land 354: 1811-1824.

Grove SJ, Stork NE. 1999. The conservation of saproxylic insects in tropical forests: A research agenda. J Insect Conserv 3: 67-74.

Guitet S, Pithon S, Brunaux O, Jubelin G, Gond V. 2012. Impact of logging on the canopy and the consequences for forest management in French Guiana. For Ecol Manag 277: 124-131.

Koivula M, Niemela J. 2003. Gap felling as a forest harvesting method in boreal forests: responses of carabid beetles (Coleoptera, Carabidae) Ecography 26: 179-187.

Larrier L, Cabanettes A, Sarthon J-P. 2015. Hoverfly (Diptera: Syrphidae) richness and abundance vary with forest stand heterogeneity: Preliminary evidence from a montane beech fir forest. Eur J Entomol 112: 755-769.

Lewis ON. 2001. Effect of experimental selective logging on tropical butterflies. Conserv Biol 15: 389-400.

Moirangthem BD, Singh SN, Singh DC. 2018. Lutzia tigripes (Diptera: Culicidae, Metalutzia) for the mosquito larval control: A new prospect of mosquito control. Intl J Mosq Res 5: 01-04.
Mlynarek JJ, Gregoire Taillefer A, Wheeler TA. 2018. Saproxylic Diptera assemblages in a temperate deciduous forest: implications for community assembly. Peerj 6: e6027. DOI: 10.7717.peerj.6027.

Niemela J. 1997. Invertebrates and boreals forest management. Conserv Biol 11: 601-610.

O’Brien MJ, Brezzi M, Schuldt A, Zhang J-Y, Ma K, Schmid B, Niklaus PA. 2017. Tree diversity drives of arthropod herbivores, but successional stage mediates detritivores. Ecol Evol 7: 8753-8760.

Okland B. 1996. Unlogged forests: Important sites for preserving the diversity of mycetophilids (Diptera: Sciaroidae). Biol Conserv 76: 297-310.

Rostaman, Permana AD, Subahar TS, Sastrodihardjo S. 2007. Biology of sciarid fly, Brodysia ocellaris (Diptera: Sciaridae), pest on oyster mushroom cropping. J Ind Plant Prot 13: 85-94.

Sist P, Nolan T, Bertault JG, Dykstra DP. 1998. Harvesting intensity versus sustainability in Indonesia. For Ecol Manag 108: 251-260.

Soler RM, Schindler S, Lencinas MV, Peri PL, Pastur GM. 2016. Why biodiversity increases after variable retention harvesting: A metaanalysis for southern Patagonian forests. For Ecol Manag 369: 161169.

Solis MA. 1999. Insects biodiversity: Perspective from the systematist. Am Entomol 45: 204-206.

Stork NE, McBroom J, Gely C, Hamilton AJ. 2015. New approaches narrow global species estimates for beetles, insects, and terrestrial arthropods. Proc Natl Acad Sci USA 112 (24): 7519-7523.

Stork NE, Srivastana DS, Eggleton P, Hodda M, Lawson G, Leakey RRB, Watt AD. 2017. Consistency of effect of tropical forest disturbance on species composition and richness relative to use of indicator taxa. Conserv Biol 31: 924-933.

Thorn S, Bussler H, Fritze M-A, Goeder P, Muller J, Weiss I, Seibold S. 2016. Canopy closure determines arthropod assemblages in microhabitats created by windstorms and salvage logging. For Ecol Manag 381: 188-195.

Willot SJ, Lim DC, Compton SG, Sutton SL. 2000. Effects of selective logging on the butterflies of Bornean rainforest. Conserv Biol 14: 1055-1065.

Van Hoesel W, Marzal A, Magallanes S, Santiago-Alorcon D. IbanezBernal S, Renner SC. 2019. Management of ecosystem alters vector dynamics and haemosporidian infections. Nature 9: 98779. www.nature/scientificreports 